\title{
MÜDAFAAYA ÖVGÜ
}

[Cenevre Hukuk Fakültesi profesörlerinden Cenevre Barosu Reisi Prof. Edmond Martin-Achard'in Cenevre'de Birleşmiş Milletler Sarayı'nda, Beynelmilel Hukukçular Kulübü (Cercle des juristes internationaux) önünde 13 Ocak 1961 günü vermiș olduğu konferansın metnini konferansçının izniyle meslekdaşlarımızın bilgisine sunuyoruz]

"Müdafaa» vazifesi teamülen bir meslekî teşekküle terettüp etmiştir. Bu teşekkül ekseriya kıskanılmış veya küçük görülmüș ve fakat belli bir iște, bir davayı müdafaa bahis mevzuu olduğunda büyüklügüünden fazla şüphe edilmemiştir. Eskiye bir nazar atfedecek olursak, daha Misirlıların, Yunanliların, Romalıların zamanında vazifeleri mahkemeler önünde maznunları müdafaadan ibaret olan kimselerin mevcudiyetini tesbit ederiz ki bu devirlerde gerek âmmece gerek \$ahıslarca yapılan ithamın fertleri nasıl bir şiddetle tehdit edebildiği bilinmektedir.

Böylece, müdafaa daima adaletin eserine iştirak etmiştir ve, Dalloz'la birlikte denilebilir ki, nerede bir adalet mevcut olmuşsa, baro herhangi bir isim altında ve ona bağlı bir müessese olarak daima onun yanında yer almıştır.

Baro, «mahsus kaide ve âdetlere ve kendilerinin serbestçe seçtikleri bir heyetin otoritesine tâbi korporasyon halinde teşkilâtlanmış avukatlar» demektir.

Julius Magnus'dan şu pasajı zikretmeme müsaade ediniz :

«Bir beşer kültürü ve başkaları hakkında hüküm verecek insanlar mevcut olduğu müddetçe, aynı zamanda tecrübele- 
riyle, ifade ve tahrir tarzlarındaki maharetleriyle, adalet talep edenlere yol gösterecek insanlar da mevcut olacaktır. Bir topluluğun vücut bulmasından itibaren, nerede ve hangi devirde olursa olsun, bir yerde hiç bir şekil ve iklime tâbi olmaksızın, diğer bir yerde pek sıkı kaidelere bağlı olarak, bir insanın diğerine verdiği bu hukukî desteği daima müşahede etmekteyiz. Avukatlık mesleğinin tarihini tetkik beșer kültürünün tarihini tetkik demektir».

Bu hükümler şüphesiz hoș ve baro için iltifatkâr hükümlerdir, fakat yanlıs olduklarını sanmıyorum. Zira bu hükümler, tabiatıyla hukuk olduğu kadar tarih, felsefe ve iktisat da ihtiva eden bir tahsilden sonra başliyan fikrî ve ilmî bir faaliyetin teveccüh ettiği gayeyi göstermektedirler. $\mathrm{Bu}$ faaliyet beșer sevgisi ve şahsiyete hürmet esasları üzerine müessestir.

Stajdan sonra hukukçu kendisine başvuracakların menfaatlerini değerlendirmek, anlamak ve müdafaa etmek için ilk silâhlarını iktisap etmiștir. O menfaatler ki, yerine göre, en azından insanların hayatı, șerefi, hürriyeti veya maddî varlıklarından başka bir şey değildirler. O insanlar ki, hukukçunun karşısında, oldukları gibi, kusurlarıyla, zaaflarıyla, ıstıraplariyla ve fakat ayn zamanda asil hamle ve emelleriyle yer almıș bulunmaktadırlar.

İnsan, hayatı boyunca ve daimî surette, zorluklara, adaletsizliklere, kaderin darbelerine, yakınının aşağılık ve kötülüğüne maruz kalır. Bunlar onun muvazenesini bozarlar ve onda, bazan aşırı reaksiyonlar husule getirirler. İște avukat, doktor gibi, din adamı gibi, oradadır; gerek müşterisine tesir ederek, gerek üçüncü șahıslar nezdinde müdahalede bulunarak ve nihayet gerek mahkemelere hitabederek, muvazeneyi iade etmeye, her șeyi tekrar yerli yerine koymaya gayret edecektir.

Avukatın himaye ettiği menfaatler, șüphesiz beșerî menfaatlerdir; fakat bu menfaatler aynı zamanda, umumiyet itibariyle, hürmete şayan menfaatlerdir.

Avukat bir ahlâkçı değildir, müşterisi hakkında hüküm vermez, sadece askerî șef gibi, verilmiş bir durumdan hareket eder ve idrâkine, ilmine, malûmatına ve tecrübesine da- 
yanarak bu durumu müdafaaya ve elinden geldiği kadar 1slah etmeğe çalıșır. Avukat bazan bizzat kendi müşterisini hasminın durumunu da nazara almaya veya yüce bir adaletin kaidelerine hürmet etmeğe sevkedecektir. Avukat adalet terazisine, hukukî delillerinin, çalışmasının, araştırmalarının, enerjisinin ağırlı̆̆ını ve keza șahsî inanıșını koyacak ve șayet tabiat kendisini bir ikna hüneriyle, bir hitabet sanatıyla teçhiz etmişse bütün bu melekelerini karşısındakini iknaya tahsis edecektir. Bizzat kendisi inanmamıș olan avukat, hitabettiği kimselere tesir etmekte çok zahmet çekecektir. Maurice Garçon'un yazdığı gibi, «inanış, belâgatin büyük kaynaklarından biridir. Bazı mübalâğacı hatiplerin kendilerini inanmıș gibi göstermeğe muvaffak olabildikleri doğru ise de, inanışın, umumiyetle taklidi mümkün olmayan ve ikna etmek için esaslı bir vasıf olan otoriteyi bahşeden bir dille konuştuğunu kabul etmek lâzımdır».

Her vekâlet münasebetinin, hususiyle doktoru veya avukatı müşterisine bağlıyan vekâletin mesnedinde itimat mevcuttur ve bu itimat, fikrine başvurulanlar için meşakkatli yükler, büyük endișeler ve ağır bir mesuliyet yaratır. Halk her zaman bu mesuliyetin ağırlığını nazarı itibare almaz ve bu mesuliyetin yıpratmadığı meslekdaşlarımızın sayı ${ }^{s_{1}}$ pek azdir.

Meseleler bizi daima takip ederler ve biri diğeri üzerine ilâve olunurlar. Harekete geçmek, bir dava açmak, istinaf ve temyiz etmek, şu şahidi dinletmek, filân delili serdetmek, falan gerekçeyi ileri sürmek lâzım mıdır ? Filân vakıaları belirtmeli mi, yoksa bu vakıalar meskût geçilebilir mi ? Meslek sırrı nerede başlar ? Müșterinin tezinden inhirafa hakkı$\mathrm{mız}$ var $\mathrm{mı}$ ? Şu muhakeme usulüne başvurursak kabule şayan olacak midir? .

Öyle haller vardır ki kararın gecikmeksizin verilmesi lâ${ }^{2}{ }^{\prime}{ }^{d}{ }_{1}$, zira hiçbir şey yapmamak vaziyet almaya muadildir. Fakat harekete geçmek de, bazan endişeli olabilecek bir yol üzerinde angaje olmak demektir ve avukat ekser zamanlar, gayretlerinin neticesine intizaren müşterisinin yükünü yalnız başına taşır. Bu gayretler, gerek hâkimlerin anlayışsızlı̆̆g yüzünden (ki teamüle göre ancak üç gün müddetle tel'ini müm- 
kündür), gerek kendisine müşkülâtsız görünen bir davanın kazanılmas ${ }^{\mathfrak{n} ı}$ tabiî bulan müvekkil tarafından takdir edilmedikleri için mükâfatlandılmış da olmazlar.

Bununla beraber, avukatlık mesleği, bu ağır külfetlere rağmen, istiklâliyle, hayatiyetiyle, husule getirdiği durumlarn tenevvüüyle, mutlak bir hürriyet içinde kendini ifade ctmenin, icabettiğinde mevkii nekadar yüksek olursa olsun herkesi tenkid etmenin ve inandırmaya çalışmanın doğurduğu zevk ile öyle bir itminan verir ki kendi arzusuyla mesleği terkedenler bu sebeple çok nadirdir.

Avukat, umumiyetle her insan gibi, bir adalet idealiyle hareket eder; fakat o, bir başkasılna nazaran, hususî hallerde, bu haller ister hususî̀ menfaatlere, ister devletin siyasì meselelerine taallûk etsin, bu adalet hissini tebarüz ettirmek ve noktai nazarm ${ }^{1}$ ifade eylemek hususunda daha fazla firsata sahiptir.

Şayet ferd için hikmetin başlangıcı jandarma korkusu ise (1), avukat korkusu da belki idare ve iktidar için hikmetin başlangıcıdır.

Bu hukukî mücadelelerde «hakikat» nerede bulunmaktadir ? Yirmi asır önce Pilate'ın (2) zihnini işgal eden ve Pirandello'nun herkese bir hakikat tanımak suretiyle halletmiş olduğu mesele (3). Bu arz üzerinde bir çok hakikat mevcut olabileceğini iddia etmek bir skandal değildir. Bilfarz kanunî hakikat, kazaî içtihadın koyduğu hakikatle, objektif hakikat subjektif hakikatle, adlî hakikat, bir majüskülle yazılan -ve ne ferd ne de hâkim tarafindan ulaşılması muhakkak olan «Hakikat» le tearuz edebilir.

Yekdiğerine zit davaların avukatlar tarafından aynı asalet ve hüsnüniyetle müdafaa edilebilmesini izah eden sebep-

(1) "La crainte du gendarme est le commencement de la sagesse» - Fransiz darbimeseli -

(2) İsa'yı, suçsuzluğuna vicdanen kani bulunmasına rağmen, mahkemeye vermek zorunda kalan Romall vali.

(3) Konferansçı, İtalyan piyes ve roman yazarı Luigi Pirandello' nun «A chacun sa vérité» adll piyesine telmihde bulunmaktadir 
leri aramak şayet gerekliyse, bu sebepler şüphesiz müdafilerin bu noktai nazar çeşitliliğinde bulunacaktır. Fakat bu sebepler, aynı zamanda gerek avukatların, vakıaların henüz tesbit edilmemiş bulunduğu bir anda, müssterilerine, bazan aşirı olarak itimat etmelerinden, gerek ekseriya bir nevi yardım etmek ihtiyacından ve nihayet onu da diyelim, bizleri bazan müvekkilin tezine kolaylıkla iltihaka sevkeden bir nevi meslekî dalâletten de doğmaktadırlar.

Fakat bizzat kendi müvekkillerine hasımlarının dahi ileri sürmeyi tahayyül etmiyecekleri delillerle karşı koyan ve işi vicdanına uygun bulmadığı için reddeden bir çok avukatın reaksiyonu da bilinmektedir. Baro Reisi Payen'in yazmıs olduğu gibi, avukat, otoritesini müdafaa ettiği, hatta kazandığı ișlerden değil, müdafaa etmeği reddettiği işlerden kazanır.

İște bazıla:ınnn yüksek vasfi aşikâr olan bu davranıșlar, adlî müdahalenin meşru, hürmete șayan ve temiz karaterini izah etmektedirler.

Şüphesiz, kazanç cazibesi avukatı bir davayı kötü niyetle takipte cesaretlendirebilir, böyle ifrat halleri de vardır. Baro sinesinde yalnız azizleri topladığı iddiasında değildir. Fakat meslekdaşlarımla münakaşa ettikçe, onları işbaşında gördükçe, mesleğimizin esaslı ve en güzel zevklerinin maddî meselelerden sıyrılmış bulunduğuna daha fazla kani olmaktayım. Tezini muzaffer kılmanın, hâkime kabul ettirilen bir içtihad ${ }^{1}$ yaratmış olmanın itminanı, bir adaletsizliği veya böyle telâkki edilmiş bir durumu telâfi etmenin sevinci, adalet faaliyetine iştirak edenler için paha biçilmez bir saadet teşkil ederler.

Bizi mesleğimize bağlıyan ve mesleği terkenlerde bazan büyük pişmanlik doğuran şey, hayatın muayyen bir gerçeğine iştirak etmek ve bu mevcudiyet içinde, tam bir istiklâl ve hürriyetle, kendilerine bir destek arayan insanlara yol gösterebilmek duygusudur.

Geniş mânada kullandığımız - zira her zaman dâva mevzuubahis olmaz-, bu dominus litis rolü, rollerin en güzeli ve en heyecan vericisidir. Bu rol, kendisini beșerî veçhesiyle olduğu kadar fikrî karakteriyle ona tahsis edenlere așk ve ih- 
tiras verir. Bir hai tarzı aramak, bir nazariye, bir deliller manzumesi inşâ etmek, muhasım bir tezi cevaplandırmaya uğraşmak ve icabında - ki bu vazifelerimizin en ehemmiyetsizi değildir - uzlaștırma yolları aramak, başkalarını anlayış gösterme gayretine icbar etmek, - ve ekseriya hasım tarafın müşaviri veya bir çok bağların bizi kendisine bağladığı hâkimle birlikte - makûl ve yapıcı hal tarzını bulmaya çalışmak, bütün bunlar fikir için olduğu kadar gönül için de tatmin edici faaliyetlerdir. Böylece avukatlar, en küçük akisleri aleniyetleri dolayısiyle ayyuka çıkan mahkeme celselerinden uzaktadırlar; avukatların ekserisinin çalıșması, yazıhanelerinin sükûtunda veya hararetli geçse dahi hususî büroların nazik atmosferi içinde, her türlü reklâmdan uzak ve ekseriya müşterilerinin giyabında cereyan eder. Ve bununla beraber, zor bir davanın hazırlığı, araştırması ve müdafaası, nasıl bir çalışma ve hazırlanmayı, nasıl bir fikrî ve teksifî gayreti icabettirir.

«Haklı dava» problemi şüphesiz nazik bir meseledir, fakat gördiuğümüz gibi her iki müdafi için de haklı dava mevcut olabilir. Birisi kanuna, diğeri kazầ içtihada, birisi kanunun lâfzına, diğeri kanunî metnin ruhuna istinad edecektir.

Bir gün bir meslekdaşımla birlikte sorgu hâkiminin bürosunda iki kişiye refakat ediyordum. Bu şahıslardan birincisi, bir otomobil kazasında, ikincisinin kzzının ölümüne sebebiyet vermiști. Her ikisi de aynı felâketle yekdiğerine bağlanmıș ve aynı felâketin altında ezilmişlerdi. Her ikisinin de adalet önünde yardıma ihtiyaçları vardı. Her ikisinin de farklı hatta zıd mesnetlerine rağmen, müdafaa edilecek bir haklı davası mevcut değil miydi ?

Haklı dâva meselesi nâzik ve prensip olarak herkesin şahsî takdirine birakılması gereken bir mesele olduğu gibi, muhakeme usulünde veya adlî mücadelede kullanılacak vasıtalar meselesi de aynı derecede nazik bir meseledir. Fakat bu mevzuda, s'kı kaidelere, meslekî âdetlere başvurmak daha kolaydır, zira bazı vasıtalar daha ilk bakıșta dürüstlükten uzak ve davanın muvazenesini bozmaya müsait bir karakter arzederler. Hususiyle, vazı kanunu normal olarak müdafilerin emniyetine tahsis edilmiş vasıtalardan onları mahrum etmeğe sevkedebilecek, davayı uzatmaya mâtuf manevrala- 
ların sistematik bir şekilde istimalini kastediyorum. Bununla beraber bir muhakeme usulünün davayı uzatıcı veya aşırı olup olmadı̆̆ını takdir yetkisi münhasıran devlete verilmemelidir. Zira bu sefer devletin, müdafaanın meşru haklarını tahdit için bu delili suistimal etmesi tehlikesi mevcuttur.

Öyle görünüyor ki bu noktada en iyi kontrolü bizzat avukatların teşkil ettiği ve usul kaidelerinin tatbikinde mükemmel bilgiye sahip, suistimal hallerinde daima bir sertlik ve ciddiyet delili vermiş olan heyetler yapabilir; bunlar da müdafiler arasında sıkı bir disiplini idameyle ve mesleğin liyakatle ve istiklâl içinde icrasını teminle vazifeli Baro İdare Heyetleridir.

Şimdi, müdafaanın rolünün bugünkü dünyada haiz bulunduğu ehemmiyeti tebarüz ettirmeğe çalışacağım. Doğrusunu söylemek lâzım gelirse, gördüğümüz gibi bu rol aslâ ihmal edilebilir duruma düşmemiştir, fakat mazinin bazı devirlerinde bu rolün herkesi aynı derecede ilgilendirmediği düşünülebilir. Yaşadığımız devir gibi hürriyetin, ferdiyetçiliğin, şahsiyetin ağır şekilde tehdit altında bulunduğu kriz zamanlarında bu aslî değerleri avukatlık mesleğinden başka hangi meslek kurtarmaya çalışabilir? Bugün ne görmekteyiz ? Siyasî, iktisadî felsefî tezlerin ekserisinin müdafaasında, sağda olduğu gibi solda, en çeşitli hereketlerin başında, mitinglerde, umumî toplantılarda, parlâmentolarda, hatta barikatlann üzerinde avukat bulunmaktadır. Şüphesiz bazı memleketlerde adalet müdafiinin sözünün tahdidine, hatta tamamiyle ortadan kaldırılmasına çalışılıyor, zira bazı rejimler muhalefete tahammül etmezler. Baro Reisi Arrighi'nin geçen Aralık ayında Paris Adalet Sarayı'nda staj konferansının açılış merasimi dolayısiyle verdiği nutkunda hatırlattığı gibi «Devlet kuvvetli oldukça, hürriyete, yani Baromuza hürmet etmeğe daha müsaittir».

Fakat devletin zayıf bulunduğu ve teşkilâtlanmış müdafaadan çekindiği bir çok devirler de olmuştur. Fransız İhtilâli baroyu tamamen ilgaya ve avukatların yerine meslekten olmayan müdafiler ikame etmeye kadar gitmişti ve bu müdafiler, Thibaudot'nun Henri Robert tarafından nakledilen ifadesiyle. «tahsilsiz ve unvansız, müșterilerini iğrenç bir tamahkârlıkla müdafaa ediyorlardı". 
Bu buhranlı devirlerde, an'anelerine sadik eski avukatların gösterdiği harikulâde cesaret malûmdur. XVI uncı Louis'nin avukatı olan ve Konvansiyon Meclisine hitaben «sizin aranızda hâkimleri arıyorum, fakat itham edenlerden başka kimse göremiyorum» ve «Șüphesiz bugün sizinkine müsavi bir kudret mevcut değildir, fakat sizde mevcut olmayan bir kudret daha var ki o da haklı olmanın kudretidir» diyen Sèze'i zikredelim.

Müdafaasını müteakip tevkif edilen, Marie Antoinette'in avukatı Chauveau-Lagarde'ı, "Konvansiyona hakikatı ve başımı getiriyorum, birinciyi dinledikten sonra ikinciye dilediğini yapabilir» diyen Berryer'i hatırlıyalım.

Günümüze yakın zamanlarda, daha nice avukat mahkemeler önünde veya parlâmentolarda, yalnız bir şahsın değil, kendilerini ve hâkimleri așan mukaddes bir dâvanin müdafileri olarak aynı şekilde cesaret delilleri vermişlerdir.

Buraya kadar sizlere avukatlık mesleğinin vasıflarından bazılarını hatırlatmaya çalıștım, fakat demeğe hacet yoktur ki bu meslek ancak bir hürriyet çerçevesi, kanunla açıkça tâyin ve tanzim edilmiş bir teşkilât ve kanunîlik dahilinde hakkiyle icra edilebilir. Bu kanunîlik avukata da tallûk eder. zira avukat bizzat dermeyan ettiği kaidelerden tecerrüt edemez. Fakat bu kanunîliğe aynı şekilde iktidar ve hâkimler de riayet etrnelidir. Zira iktidar beşer şahsiyetine hürmet etmez ve demokratik kanunlar çıarmazsa, hâkimler muistakil değillerse ve hakka hürmet etmezlerse, müdafilerin gayreti, onların müdafaa yapmalarına müsaade edildiği farzedilse dahi, muvaffakıyetsizliğe mahkûm olacaktır.

Dünyamız, şimdiye kadar oliduğundan çok daha fazla, herkesi modern tekniğin terakki ve buhranlarına intibak ettirmeğe çalışacak hukukçulara muhtaçtır. Avukat Flavien Lalive'in hatırlattığ́ı gibi «hukukçuların rol ve vazifelerinin gittikçe artan bir ehemmiyet ve müstaceliyet kazandığı bir dünyada yaşıyoruz» ve hukukçular arasında müdafaanın rolü daima daha büyük bir vüs'at kazanmaktadır. Baro Reisi Arrighi meslekdaşlarına şunu diyordu: «Sizler öyle bir kâinat içinde yașıyorsunuz ki bu kainatta müstevli bir teknokrasi tarafından desteklenen despotluğun bütün çeșitleri karșlaş- 
maktadır. Yaşadığımız dünya ferd ve kitle arasında bir muvazene kurmaya çalışmakta ve bu muvazeneyi ne ferde ne de kitleye tamamen feda etmek istemektedir. İşte bu şartlar içinde sizler bir ferdin hürriyetini müdafaa edeken aynı zamanda insan hürriyetlerini müdafaa etmektesiniz».

"İște vazifemizin asalet ve nezaketi budur: Bir karınca yuvasını andıran kitleye karşı ferdi ele alarak insan haysiyet ve hürriyetini, bu haysiyet ve hürriyetin ancak herkesin bir ferd için, bir ferdin herkes için haiz olacağı karşılıklı hürmet ve hizmet anlayıșı üzerine kurulu ve teşkilâtlanması ve yükseltilmesi devlete ait olan bir cemiyette serpileceğini, idame edeceğini ve büyümeğe devam edeceğini unutmaksızın müdafaa etmek».

Asırlardanberi avukatların an'anevi müdahalelerine ve Baroların sağlam teşkilâtına alışmış olan bizim memleketlerimizde dahi, müteyakkız olmak şarttır; zira devlet, gittikçe artan bir şekilde, ferdlerin imtiyazları üzerinde hak iddia etmektedir. Pek farklı bir hukuk telâkkisine sahip olan Doğu memleketlerine gelince, öyle görünüyor ki bu memleketler de her zamankinden daha ziyade, bir nev'i kanunîlik prensibi telâkkisiyle, bir hukukî emniyet ihtiyacını şiddetle hissetmektedirler. Şüphesiz bu memleketlerin kanunlarnnı, müsbet hukuklarının muhtevası bizim batı mevzuatımızdan ehemmiyetli șekilde farklıdır, fakat tezahür eden bu kanunîlik arzusu dikkatimizi çekmemezlik edemez.

Hukukçuların faaliyeti hususiyle genç memleketlerde kendini gösterebilir ve göstermelidir ve bu mevzuda temenni edilir ki dünyanın diğer milletlerine bazan pek kötü örnekler vermiş olan ihtiyar Avrupamız, malik olduğu iyi șeyleri, yani asil ve menfaatten uzak bir ruh içinde şahsiyete hürmet esası üzerine müesses asırdide bir kültürün meyvalarını bu memleketler için muhafaza etmesini bilecektir.

Ancak, genç milletlerin ahenkli inkişafyyle ilgilenen yalnız Avrupa değildir. Büyük ve zengin bir maziye sahip diğer memleketler de bu mevzuyla endișelenmektedirler. Burada 1959 yllında Yeni Delhi'de toplanan ve Avrupalı hukukçuların yanında, Hindistan, Pakistan, Seylân, Endonezya, Singapur, Malezya, Vietnam, Kamboç, Birmanya, Lübnan, Fas, Libya, 
Birleşik Arap Cumhuriyeti ve Afrika hukukçularından teşekkül eden Yeni Delhi kongresinin bazı kararlarını hatırlatmak benim için bir zevk teşkil edecektir. Aşağı yukarı 50 memleketten ve dünyanın bütün kıt'alarından gelen bu hukukçular, yetişme tarzlarının, fikirlerinin, karșılıklı durumlarının tenevvüü içinde bir hareket noktası, müşterek bir mahreç aramişlar ve herşeyden evvel herkes için kabule șayan bir kanunîlik prensibi telâkkisi, beșer haysiyetinin hürmet göreceği bir düşünce tarzı ve cemiyetin bütün azalarına temin edilen âdil hayat şartları üzerinde anlaşmaya gayret etmișlerdir.

Bu kongrede konuşan Hindistan Başsavcısı, eski hukuk kitaplarımızın kanuna kralın fevkinde bir yer verdiğini hatırlattı ve kanunilik prensibini târife çalışarak ferdin haklarının ve haysiyetinin ancak serbest seçimlerin mevcut olduğu ve kanunların halk tarafından usulüne uygun olarak seçilen mümessillerce yapıldığı memleketlerde korunabileceğini belirtti ve șunları ilâve etti : «İnsan haklarına hürmeti teminat altına alan ve onların tatbikine müsaade eden aslî hürriyetler, ancak adaletin müstakil hâkimler tarafından icra edildiği ve baronun bu hürriyetleri tanıtmak hususunda ferde yardım etmeğe ehil ve arzulu bulunduğu memleketlerde neşvünema bulabilir».

Hindistan Başvekili Pandit Nehru ise, cemiyetin tekâmül ettiğini, sınaî ve teknik terakkiler neticesinde șekil değiștirdiğini ve mevzuat bu duruma kendisini kâfi derecede sür'atle intibak ettirmediği takdirde teknik terakki gibi faktörlerin tazyiki ile maziye ait bir hürriyetle cemyetin tekâmülïi arasında br uçurum husule geleceğini belirtmekle beraber, kanunun medenî hayatın temeli olduğu vakıası üzerinde israr etti. Bizzat hukuk da, bazı daimî prensipler istisna edilirse, tekâmül etmektedir. Bu sebeple istikrar ve değişme aynı tempoda yürümelidir. Kanunîlik prensibi herkese eşit muamele yapılmasını, her türlü ırk tefrikinin ortadan kalmasını, insan haklarının himayesini gerektirir.

Nihayet Nehru şu neticeye vardı ki, bütün bunlar, hukukun üstünlüğünün beșer șahsiyetinin üstünlüğünün yalnı bir veçhesini teșkil ettiği düșüncesine müncer olmaktadır. Kanunîlik prensibi ne hayatın problemlerinden tecerrüd edebilir 
ve ne de bugün zamanı geçmiş meselelerle vakit kaybedebilìr. Bu prensip bugünkü dünyanın meselelerini karşılamak zorundadir.

Isste Delhi Kongresi'nin kendisini vakfettiği vazife bu ol. muştur. Kongre, kanunîlik prensibinin hususiyle ceza usulü ile münasebetini inceliyerek ferdin kendini müdafaa etmek hakkını teyit etmiștir. Kongrenin vardığı neticelere göre bu prensibin bir ceza davasına ithal ettiği esaslar şunlardır :

1. Maznunun davanın her halinde kendi seçtiği bir müşavirin yardımından faydalanmaya ve onunla tam bir hürriyet içinde temasta bulunmaya hakkı olmalıdır;

2. Aleyhindeki itham sebepleri sarahatle kendisine bildirilmelidir;

3. Müdafaa şahitleri ikamesine ve onlann sorgusunda hazır bulunmaya hakkı olmalıdir :

4. Hiç olmazsa ehemmiyetli ișlerde davadan evvel ve zamanında, iddia makamınca toplanmış dava unsurlanının mahiyeti kendisine tebliğ edilmelidir;

5. Iddia şahitlerinin sorgusunda hazır bulunmaya veya onları tekrar dinletmeye hakkı olmalıdır.

İfade edilen diğer esaslı prensipler şunlardır :

a) Hiçbir maznun veya şahit maddî veya ruhî bir cebre tâbi tutulamaz.

b)Ceza davası, kanunun derpiş ettiği istisnalar mahfuz olmak üzere, alenî cereyan etmelidir,

c) Matbuat ceza dâvasının safahatını nakledebilmelidir, ancak gerek davadan evvel ve gerek dava sirasında davanın bitaraf cereyanına halel vermeğe müsait her türlü haberin neşrine müsaade, kanunilik prensibiyle bağdaşmaz.

d) Her ceza mahkûmiyeti ve tahliye talebini reddeden her karar aleyhine en az bir müracaat yolu mevcut olmalıdır.

e) Kanunilik prensibine hürmet edilmesini temin için, bir nizama bağlanmış, kendi faaliyetlerini serbestçe kendileri tanzim eden hukukî mesleklerin mevcudiyeti elzemdir. 
Nasıl bir adalet telâkkisine sahip olunursa olunsun, nasıl bir sisteme bağlanılırsa bağlanılsın, bu tezlerin doğruluğuna muhalefet edilebileceğini sanmıyorum. Ne bahtiyarlıktır ki bu tezler 50 memleketin seçkin hukukçuları tarafından Mahatma Gandi'nin memleketinde münakaşa ve kabul edilmiştir.

Yakında Nijerya'da yeni bir toplantı akdetmiș olan Beynelmilel Hukukçular Komisyonu'nun (4) Hindistan başşehrinde iki yll önce toplanan Kongre'sinden bu uzun izahatı, beni dinlemekle bana şeref bahşeden ünlü hukukçulara, hiç kimsenin dünyanın bugün vazettiği çetin problemlere bigâne kalamıyacağını belirtmek için verdim. Bu problemler, hususiyle, beșerî münasebetlerin âmir ve nâzımı olan hukukçulara, daha hususî olarak da avukatlara tallûk etmektedir. Müdafaanın rolü daima büyümektedir ve her memlekette kendini teyid ettirmelidir. Vazifelerinin maziye intikal etmiş bir vazife değil, her gün daha büyük gerçeklik ve nüfuz iktisab eden bir vazife olduğunu düşünmek bilhassa genç avukatlar için heyecan ve ihtiras vericidir.

Mazideki büyüklüğünden hiçbir şey inkâr etmeksizin, Müdafaa, aynı ruhla, yeni vazifelerde mücadeleye âmade bulunmaktadır.

(4) Beynelmilel hukukçular komisyonu, Birleșmiş Milletler ekonomik ve sosyal konseyi nezdinde B kategorisinin istişarî statüsünü haiz, hükûmet dişı ve siyasî karakteri olmayan bir ıeşekküldür. Gayesi, hukukun üstünlüğunü ve bir kanunilik rejimini desteklemek ve terakki ettirmektir. Azalarının sayısı azamî 25 olarak tesbit edilmiştir. Komisyon 1952'de kurulmuş ve daimî sekreterliği La Haye'de yerleşmişti. 1959 yllinda bu daimî sekreterlik Cenevre'ye nakledildi, merkezi rue du Montde Sion No, 6'da bulunmaktadir.

Komisyonun kesif bir faaliyeti vardır. Hususiyle bir bülten, bir dergi, bir haberler bülteni ve hususî incelemeler ve raporlar neşreder. Komisyon vasitasiyle bir buçuk milyondan fazla döküman tevzi edilmiş bulunmaktadır. Genel Sekreterlik vazifesi 1958-1961 yullarında Cenevre Barosu avukatlarindan Dr. Jean Flavien Lalive tarafından ifa edilmiştir. Konsey âzaları arasında bir çok avukat bulunmaktadir. (Revue International de Criminologie et de Police Technique vol. XV, No. 2, s. 97 den). 